\title{
Experimental studies on the disintegration of high-clay sands and the enrichment of heavy minerals in an experimental scrubber-free washing plant
}

\author{
Grigoriy Shirman ${ }^{1 *}$, Andrey Matveyev ${ }^{1}$, Natalia Eremeyeva ${ }^{1}$, Igor Matveyev ${ }^{1}$ and Oleg \\ Ochosov $^{1}$ \\ ${ }^{1}$ The Chersky Mining Institute of the North, Siberian Branch, the Russian Academy of Sciences, \\ laboratory "Concentration of Mineral Wealth”, 43 Lenin Str., Yakutsk, Republic of Sakha (Yakutia), \\ 678980
}

\begin{abstract}
The Chersky Mining Institute of the North, Siberian Branch, the Russian Academy of Sciences offered for development a new type of scrubber-free washing device, focused on the processing of gold-bearing sands with a high content of silty-clay fractions. The wash plant includes a disintegration and classification device, a steeply inclined concentrator and a centrifugal vibration concentrator. Experimental tests on a model unit made it possible to obtain end-to-end acceptable values for sand disintegration and gold concentration. The results obtained showed the possibility of obtaining a concentrate with a gold recovery of $70.31 \%$ at a rational productivity of the model of $2 \mathrm{~m}^{3} / \mathrm{h}$.
\end{abstract}

Keywords: clay, high-clay sands, washing, disintegration, beneficiation, placer.

\section{Introduction}

One of the features of deposits with difficult-to-process raw materials is the high content of clay impurities, which complicate the extraction of useful components. Along with this problem, such deposits are also characterized by the presence of fine gold fractions. The problem of processing and concentration of sands for this type of deposits is associated with the actual absence of highly efficient devices for washing and extracting fine and thin gold.

Currently, scrubber-type devices are widely used for the disintegration of high-clay sands, however, as practice shows, during the washing process there has been observed a formation of secondary clay formations in scrubbers - dense rounded pellets [1], which bring valuable components to a pebble dump with non-disintegrated material (losses of precious metal being over 20\% [2,3]), and insufficient disintegration of the sands leads to the fact that clay fractions are fed to the concentration equipment, increasing the viscosity and disrupting the capture of heavy fractions. In particular, at sluices an excessive amount of clay leads to silting of the cells of the mats and, accordingly, reduces the quality of sluicing operation. Part of clay conglomerates, moving with the flow along the catching surface, is capable, due to

* Corresponding author: shirman@inbox.ru 
the excess adhesion properties, to capture settled gold particles from the stencils, dragging them along into the dredging tailings.

The experience of various concentration equipment in the development of alluvial deposits with a high content of fine and thin gold showed that when using traditional equipment, losses of this category of gold can reach 54\% [4].

A new type of scrubber-free washing device for processing gold-bearing sands with a high content of silty-clay fractions has been proposed for development by the INM of the SB RAS. The industrial device includes the following equipment with the original design by the Institute: disintegration and classification device (DCD), steeply inclined concentrator (SIC) and centrifugal-vibration concentrator (CVC).

A diagram of a prototype (model) of the new industrial device (technological unit) with the expected parameters of technological flows is shown in Fig. 1.

Primary sands

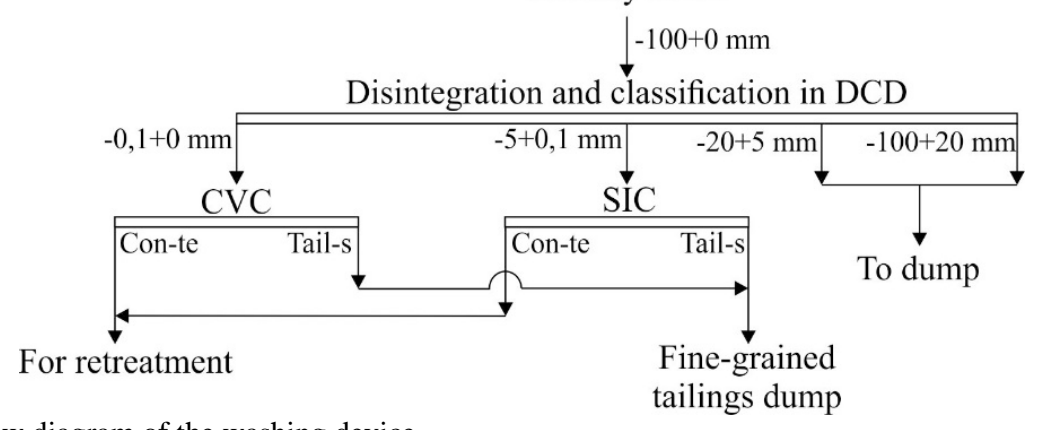

Fig. 1. Flow diagram of the washing device.

The head unit of the industrial device is the disintegration and classification device (DCD), using a complex sequential effect on the washed material in air and water-air environments as the principle of operation. The device provides disintegration, hydraulic classification and removal of slime fractions.

The main enrichment equipment in the scrubber-free industrial device is a steeply inclined concentrator (SIC), in which the separation of minerals occurs on ascending water flows along a steeply inclined surface, which makes it possible to reorient flattened particles in the pulp flow and increase their hydraulic size. Increasing the hydraulic size makes it possible to recover refractory flattened and flaky forms of gold, which are typical for most placer deposits.

To enrich the slurry products of the disintegration and classification device, a centrifugalvibration concentrator of a new design, capable of working with a viscous flow, is used. The design feature is to control the state of the trapping bed through the use of directional vibrational fluctuations, ensuring the most effective conditions for trapping fine and thin gold.

In laboratory conditions, stands and models were manufactured and tested, enabling to identify the rational design parameters of the proposed devices and showing the fundamental possibility of their performance. On the basis of laboratory models, large-scale laboratory models were made and tests were carried out, which made it possible to make a number of proposals for modernization in the design of the equipment.

The installation of the scrubber-free washing device was carried out at the experimental base of the MIN of the SB RAS (Fig. 2). 


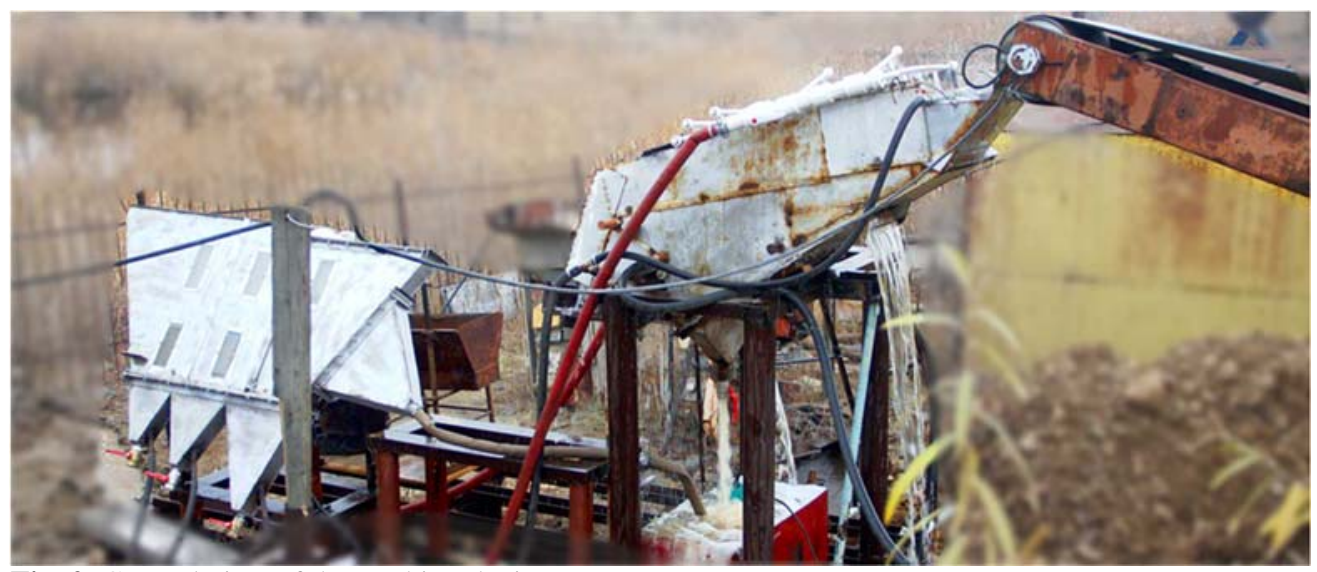

Fig. 2. General view of the washing device.

\section{Methodology of Experimental Study:}

In order to obtain rational qualitative technological indicators, experimental studies were carried out according to the developed method using a sample from the buried placer deposit of the Big Kuranakh river, located in the Aldan district of Sakha Republic (Yakutia). The material is characterized as highly clayey, containing fine and thin gold. Table 1 shows the weighted average sieve composition of gold.

Table 1. Weighted average sieve composition of gold in the sands of the placer of the Bigriver.

\begin{tabular}{|c|c|c|c|c|c|c|c|}
\hline $\begin{array}{c}\text { Size distribution, } \\
\mathrm{mm}\end{array}$ & +2.0 & $-2.0+1.0$ & $-1.0+0.5$ & $-0.5+0.25$ & $-0.25+0.1$ & -0.1 & Total \\
\hline $\begin{array}{c}\text { Mass fraction of } \\
\text { gold, \% }\end{array}$ & 0.5 & 5.0 & 13.0 & 31.0 & 34.0 & 16.5 & 100.0 \\
\hline
\end{tabular}

The procedure for performing experimental studies is as follows:

An initial sample of a certain weight and moisture content is fed by a conveyor onto the DCD loading chute. The material moving sequentially in the working area of the device is exposed to the intense action of jets of water and air in the bubbling mode and disintegrates. The DCD separation products are: washed pebble fractions $+20 \mathrm{~mm}$, slime fractions and productive sands. Pebble and slime fractions are dumped, and productive sands are converted to concentration at SIC. Primary coarse concentration takes place at SIC, concentrates are collected in the bottom part, and light fractions are carried away from the concentrator by the flow (Fig. 3). 

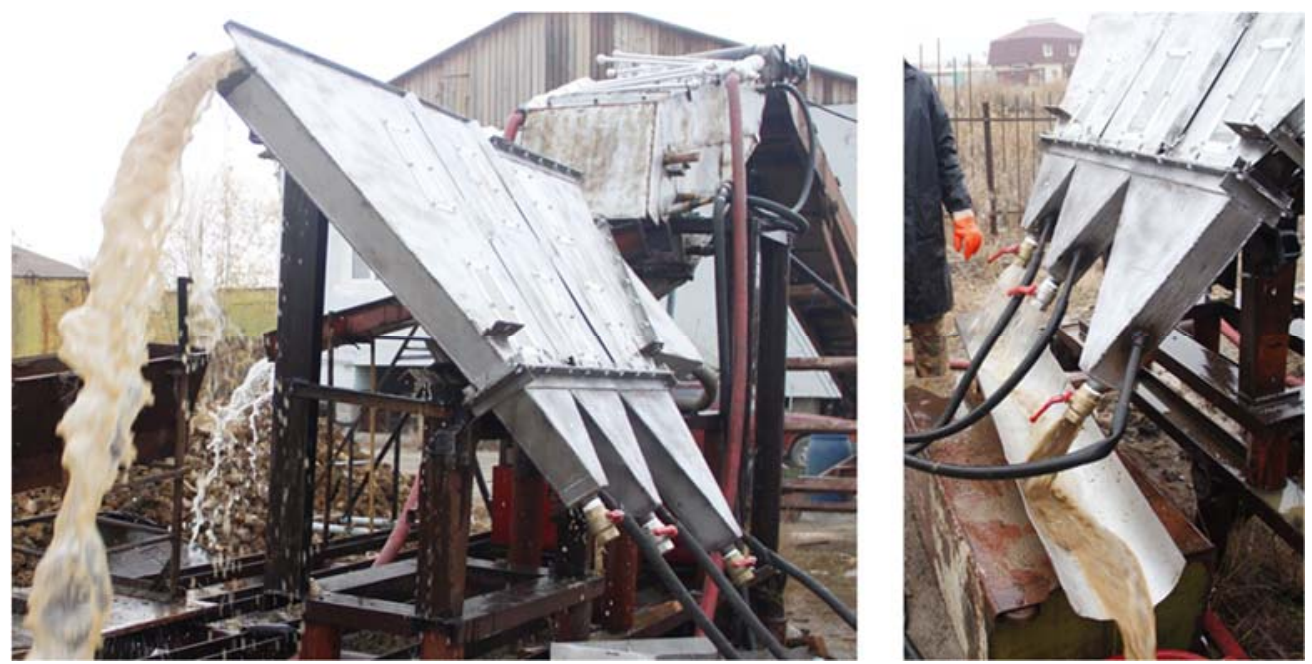

Fig. 3. Discharge of slime fractions and discharge of SIC's concentrate.

Drainage from the DCD in the form of pulp slurry enters the rotating operating body of the CVC, heavy grains are concentrated inside the concentrator riffle, and light particles are discharged through the unloading device. The operations of the concentrators were tested in the modes of continuous and periodic unloading.

During the tests, the efficiency of screening was assessed for size classes $-100+20 \mathrm{~mm}$ and $-20+5 \mathrm{~mm}$, as well as the content of fine fractions $-0.050+0 \mathrm{~mm}$ in productive sands $-5+$ $0.1 \mathrm{~mm}$, which shows how effectively the removal process is flowing for drainage of the clay component of the original material, that is, enabling to estimate the preliminary reduction.

Registration of the device's operation parameters occurs via taking technological samples in accordance with the sampling scheme, characterizing the technological product under study with a sufficient degree of reliability.

\section{Results}

Experimental work has shown that the most rational operating mode in terms of productivity is $2 \mathrm{~m}^{3} / \mathrm{h}$, at which a high screening efficiency is achieved in size classes $-20,-5$ and $-0.1 \mathrm{~mm}$ (86.23\%, 80.57\% and $92.31 \%$ respectively).

The rational productivity of the industrial device model has been identified to achieve the value of screening efficiency and gold recovery close to the maximum. An increase in productivity over $2 \mathrm{~m}^{3} / \mathrm{h}$ leads to losses of a valuable component with size classes $-100+20$ $\mathrm{mm}$ and $-20+5 \mathrm{~mm}$ at the washing stage, because at high power consumption by the industrial device the material does not have time to completely disintegrate and carries away the gold, associated with clay components, into the tailings. With a decrease in productivity from 2 to $1.5 \mathrm{~m}^{3} / \mathrm{h}$ the screening efficiency remained approximately at the same level. The rational value of the total gold recovery by the industrial device was $70.31 \%$. By contrast, this value is $70.85 \%$ when the capacity is reduced to $1.5 \mathrm{~m}^{3} / \mathrm{h}$.

As the experience of using dredges with a developed gravity concentration scheme with jigging and concentration tables at the placer deposit of the Big Kuranakh river shows, actual gold losses can reach $50-60 \%$.

The results obtained showed the possibility of obtaining a concentrate with a gold recovery of $70.31 \%$ at a productivity of $2 \mathrm{~m}^{3} / \mathrm{h}$, enabling to speak of the fundamental opportunityto use a scrubber-free industrial device for concentrating high-clay material. 


\section{Conclusion}

The main technical and technological advantages of the new type of industrial device in comparison with the existing traditional equipment are effective disintegration of clay materials, excluding secondary formations (pellets), high specific productivity and recovery rates, as well as the absence of moving parts in the washing and main concentration units. In addition to low capital operating costs, the device is characterized by a simple design and maintenance, as well as reliable operation and maintainability. Further experimental R\&D will be aimed at the development of enlarged equipment samples scaling the productivity of the industrial device as a whole.

\section{References:}

1. A.I. Matveyev, G.V. Shirman, Mining Information and Analytical Bulletin, 10, 266 (2011)

2. O.V. Zamyatin, A.G. Lopatin. Concentration of gold-bearing sands and conglomerates, (1975)

3. L.A. Mitin, G.A. Zholents, Concentration of ores, 4, 23 (2000)

4. A.V. Surkov, A.A. Akhapkin, Non-Ferrous Metals, 1, 13 (2003) 